\title{
Tn2440, a Composite Tetracycline Resistance Transposon with Direct Repeated Copies of IS160 at its Flanks
}

\author{
By B. A. NIES, J. F. MEYER AND B. WIEDEMAN N* \\ Institut für Medizinische Mikrobiologie und Immunologie der Universität Bonn, \\ An der Immenburg 4, 5300 Bonn, FRG
}

(Received 23 January 1985 ; revised 18 March 1985)

\begin{abstract}
The tetracycline resistance region of the multi-resistance plasmid pBP16 is flanked by direct repeats of the insertion sequence IS 160 . The tetracycline resistance region plus the flanking IS elements can transpose as a discrete unit. The composite transposon, designated $\operatorname{Tn} 2440$, has a size of $4.0 \mathrm{~kb}$.
\end{abstract}

\section{INTRODUCTION}

According to Kleckner (1981), transposons (Tns) can generally be divided into two main classes, class II elements, like Tn 3 and $\operatorname{Tn} 21$, with short inverted repeats at their ends, and composite class I transposons that carry insertion sequences (IS elements) at their flanks in either direct or inverted orientation, like $\operatorname{Tn} 9, \operatorname{Tn} 10, \operatorname{Tn} 5$ or Tn903. In most transposons that are flanked by direct repeated copies of IS elements, IS 1 has been identified as the element providing transposition functions; some of these transposons seem to be derivatives of $\operatorname{Tn} 9$ (Iida et al., 1981; Rosner \& Gottesmann, 1977; Reif, 1980). Two composite transposons with direct repeats of IS elements that share no homology with IS 1 are the kanamycin resistant transposons Tn 1525 (Labigne-Roussel et al., 1983) and Tn2680 (Iida et al., 1982). The flanking IS elements in these cases (IS15 and IS26, respectively) are hornologous to the recently isolated insertion sequences IS46 from R46 (Brown et al., 1984) and IS 160 from pBP16, a multi-resistance plasmid related to R46 (Nies et al., 1985). In pBP16, four copies of IS160 have been identified, two of them flanking the tetracycline resistance region as direct repeats. In this paper we describe the transposability of tetracycline resistance from pBP16.

\section{METHODS}

All methods, including plasmid DNA preparations, cloning experiments, transformation and conjugation have been described before (Meyer et al., 1983). The bacterial strains and plasmids used are listed in Table 1.

Resistance towards different drugs are abbreviated as follows: $\mathrm{Ap}^{\mathrm{r}}$ (ampicillin), $\mathrm{Su}^{\mathrm{r}}$ (sulphonamides), $\mathrm{Sm}^{\mathrm{r}}$ (streptomycin), $\mathrm{Tc}^{r}$ (tetracycline), $\mathrm{Tp}^{\mathrm{r}}$ (trimethoprim), $\mathrm{As}^{\mathrm{r}}$ (arsenate), $\mathrm{Km}^{\mathrm{r}}$ (kanamycin) and $\mathrm{Nx}^{\mathrm{r}}$ (nalidixic acid). Transfer functions and replication region are abbreviated to Tra and Rep, respectively.

\section{RESULTS AND DISCUSSION}

Plasmid pBP16 and its derivative pBP18 contain four copies of the insertion sequence IS 160 in inverted and direct orientation. Via a recombination using two direct repeated copies of IS 160, pBP15 (size 12.0 kb) can dissociate from either pBP16 (Fig. 1) or pBP18. In pBP15, as in $\mathrm{pBP} 16$, the tetracycline resistance region $(2.3 \mathrm{~kb})$ is flanked by two IS 160 elements $(0.85 \mathrm{~kb})$ in direct repeat (Fig. 1; Nies et al., 1985). Since the two IS160-related elements IS15 (LabigneRoussel et al., 1983) and IS26 (Iida et al., 1982) are components of the composite $\mathrm{Km}^{\mathrm{r}}$ transposons $\operatorname{Tn} 1525$ and $\operatorname{Tn} 2680$ it was reasonable to assume that the tetracycline resistance region of pBP15 (and pBP16) might also be transposable. 
Table 1. Bacterial strains and plasmids

Bacterial strains

Escherichia coli JC2926 Escherichia coli $\mathrm{C} 600$

Plasmids

R751

pNO1523†

pBP16

pBP18+

pBP15

pBP153:

pBP1531

pBP1532
Relevant phenotypes*

$\mathrm{Sm}^{\mathrm{r}} \mathrm{Rec} \mathrm{A}^{-} \mathrm{Thi}^{-} \mathrm{Thr}^{-} \mathrm{Arg}^{-} \mathrm{His}^{-} \mathrm{Leu}^{-} \mathrm{Lac}^{-}$

$\mathrm{Sm}^{r} \mathrm{Nx}^{\mathrm{r}} \mathrm{Rec} \mathrm{A}^{-} \mathrm{Thi}^{-} \mathrm{Thr}^{-} \mathrm{Leu}^{-} \mathrm{TonA}^{-} \mathrm{Lac}^{-}$

$\mathrm{Tp}^{\mathrm{r}} \mathrm{Tra}^{+}$

$\mathrm{Ap}^{r} \mathrm{Sm}^{\mathrm{s}}$

$\mathrm{Ap}^{r} \mathrm{Su}^{r} \mathrm{Tc}^{r} \mathrm{As}^{r} \mathrm{Sm}^{r} \mathrm{Tra}^{+}$

$\mathrm{Ap}^{r} \mathrm{Su}^{\mathrm{r}} \mathrm{Tc}^{r} \mathrm{As}^{r} \mathrm{Tra}^{+}$

$\mathrm{Tc}^{r}$

$A p^{r} T c^{r}$

$T c^{r} T p^{r}$

$T c^{r} T p^{r}$
Reference

Bachmann (1972)

Bachmann (1972)

Meyer \& Shapiro (1980)

Dean (1981)

Nies et al. (1985)

Nies et al. (1985)

Nies et al. (1985)

This paper

This paper

This paper

* See Methods for abbreviations.

$\dagger$ pNO1523 confers streptomycin sensitivity by the allele $r p s L-31$.

$\ddagger$ Streptomycin resistance is only mediated by pBP 16, although the resistance gene $(a p h)$ is also present in pBP18, pBP15 and pBP153; in the latter cases the aph gene is not expressed (Nies et al., 1985).

Since pBP15 is mobilizable by complementation of defective tra functions, it is not particularly suitable as a transposon donor molecule. Accordingly, the tetracycline resistance region plus the flanking IS elements was cloned, using SmaI, into the $r p s L$ gene of pNO1523 (Dean, 1981), a plasmid which confers ampicillin resistance (Fig. 1). The recombinant plasmid (designated pBP153) was transferred to Escherichia coli JC2926 (RecA ${ }^{-}$) harbouring the conjugative trimethoprim resistance plasmid R751 (Meyer \& Shapiro, 1980). In matings with $E$. coli JC2926 (R751, pBP153) as donor and E. coli $\mathrm{C} 600\left(\mathrm{Nx}^{\mathrm{r}}\right)$ as recipient, $\mathrm{Nx}^{\mathrm{r}} \mathrm{Tp}^{\mathrm{r}} \mathrm{Tc}^{\mathrm{r}}$ transconjugants were obtained at a frequency of $5 \times 10^{-6}$, compared to the number of $\mathrm{Nx}^{\mathrm{r}} \mathrm{Tp}^{\mathrm{r}}$ transconjugants (R751 transconjugants) obtained. To distinguish cointegrate mobilization from transposition of the presumptive $\mathrm{Tc}^{r}$ transposon, 400 colonies were replicated to test for ampicillin resistance; 395 of these clones were $A p^{r}$. Plasmid analysis of some representative clones revealed that all contained a single, large plasmid. These plasmids were identified as cointegrates of R751 and pBP153, mediated by IS160 (data not shown).

Analysis of the plasmid content of the five remaining $\mathrm{Ap}^{\mathrm{s}}$ clones showed that three of them contained two plasmids each, one the size of R751 (about $50 \mathrm{~kb}$ ) and one of approximately $20 \mathrm{~kb}$. The smaller plasmid in each isolate possibly represents pBP153 with Tn402 (from R751; Meyer \& Shapiro, 1980) inserted into the bla gene of pBP153.

Two of the Aps clones harboured plasmids (pBP1531 and pBP1532) slightly larger than R751. The PstI restriction pattern of these plasmids (Fig. 2) revealed that the tetracycline resistance region and both the flanking IS 160 copies had, in each case, inserted into PstI fragment $C$ of R751. Due to this insertion pBP1531 and pBP1532 contain three additional PstI fragments compared to R751. The smallest one resembles the internal Pst I fragment of the insertion, located between the PstI sites within the IS160 copies (identical with the largest PstI fragment of pBP153, fragment $a$ ). The other two fragments comprise the sequence located between these $P$ st I sites and the sites which define R751 PstI fragment $C$. The different sizes of these fragments in $\mathrm{pBP} 1531$ and $\mathrm{pBP} 1532$ indicate the transposition of the IS 160 -flanked tetracycline resistance region of pBP15 into different sites of $\mathrm{R} 751$. In agreement with the plasmid reference centre the IS160-flanked tetracycline resistance region has been designated Tn2440. To our knowledge $\mathrm{Tn} 2440$ is the first $\mathrm{Tc}^{\mathrm{r}}$ transposon isolated with direct repeated copies of an IS element at its flanks. Although mediating tetracycline resistance, $\mathrm{Tn} 2440$ is more closely related to the $\mathrm{Km}^{\mathrm{r}}$ transposons $\operatorname{Tn} 1525$ and $\mathrm{Tn} 2680$ than to the composite $\mathrm{Tc}^{\mathrm{r}}$ transposon Tn10 (Foster et al., 1981), on the basis of the properties of the flanking elements and their direct orientation.

From the results available for IS160 (Nies et al., 1985) and the related elements IS46, IS15, IS154, IS26 and IS140 (Brown et al., 1984; Labigne-Roussel et al., 1983; Labigne-Roussel \& Courvalin, 1983; Iida et al., 1982; Bräu \& Piepersberg, 1983) it is probable that these insertion 


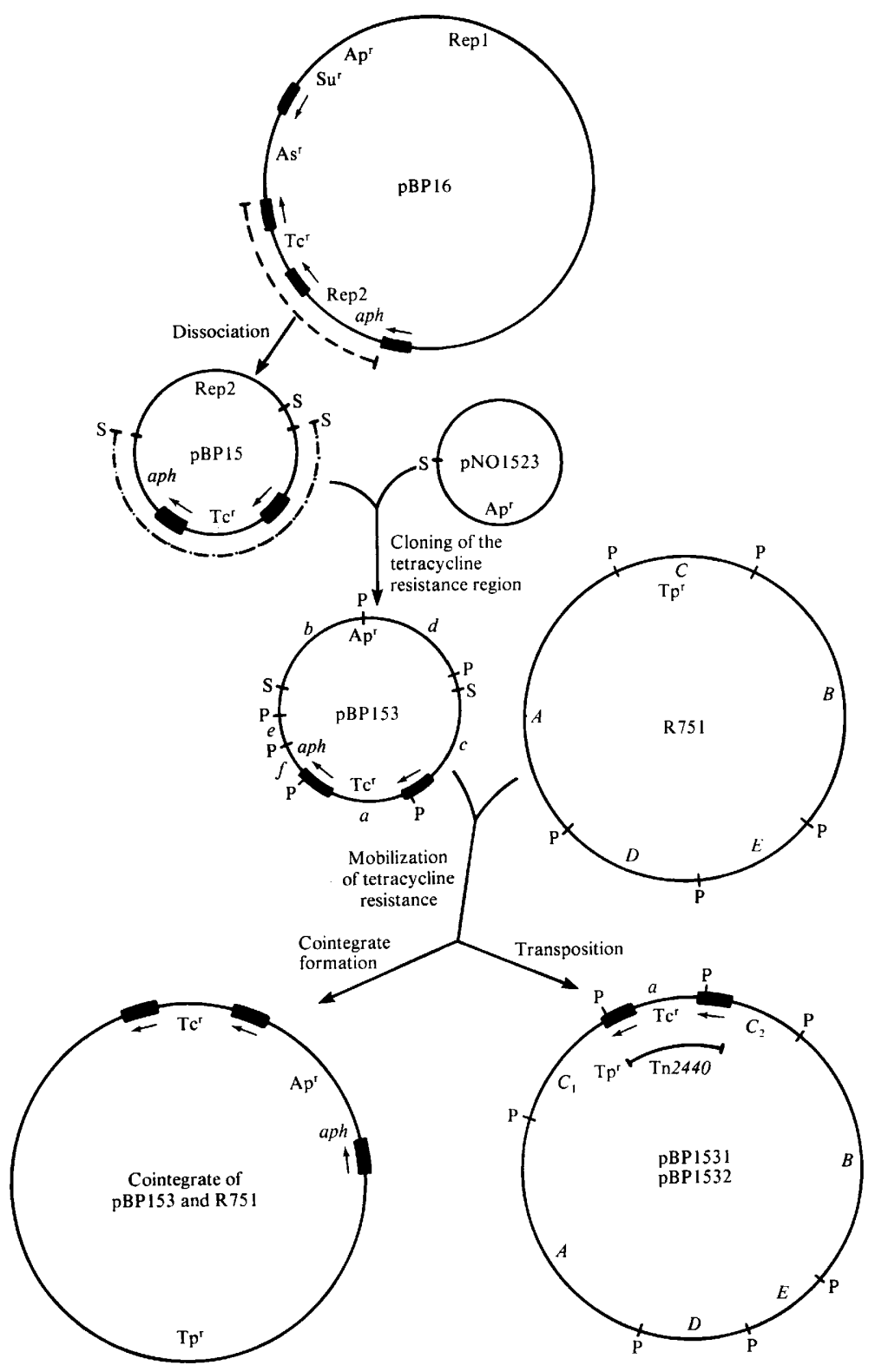

Fig. 1. Isolation of $\operatorname{Tn} 2440$. The solid boxes represent copies of IS 160 and the arrows indicate their orientation. Plasmid pBP15 was formed by dissociation of the tetracycline resistance and Rep2 regions from pBP16. The tetracycline resistance region of pBP15 was cloned with SmaI (S) into pNO1523 to generate plasmid pBP153. Mobilization of tetracycline resistance from pBP153 by R751 was due to two mechanisms, cointegrate formation via IS 160 or transposition of $\mathrm{Tn} 2440$. In the representations of pBP153, R751 and pBP1531 the PstI sites (P) and fragments (Fig. 2) are indicated. Streptomycin resistance is mediated only by $\mathrm{pBP} 16$, although the resistance gene $(a p h)$ is also present in pBP15, pBP153 and in cointegrates of pBP153 and R751; in the latter cases the aph gene is not expressed (Nies et al., 1985). 


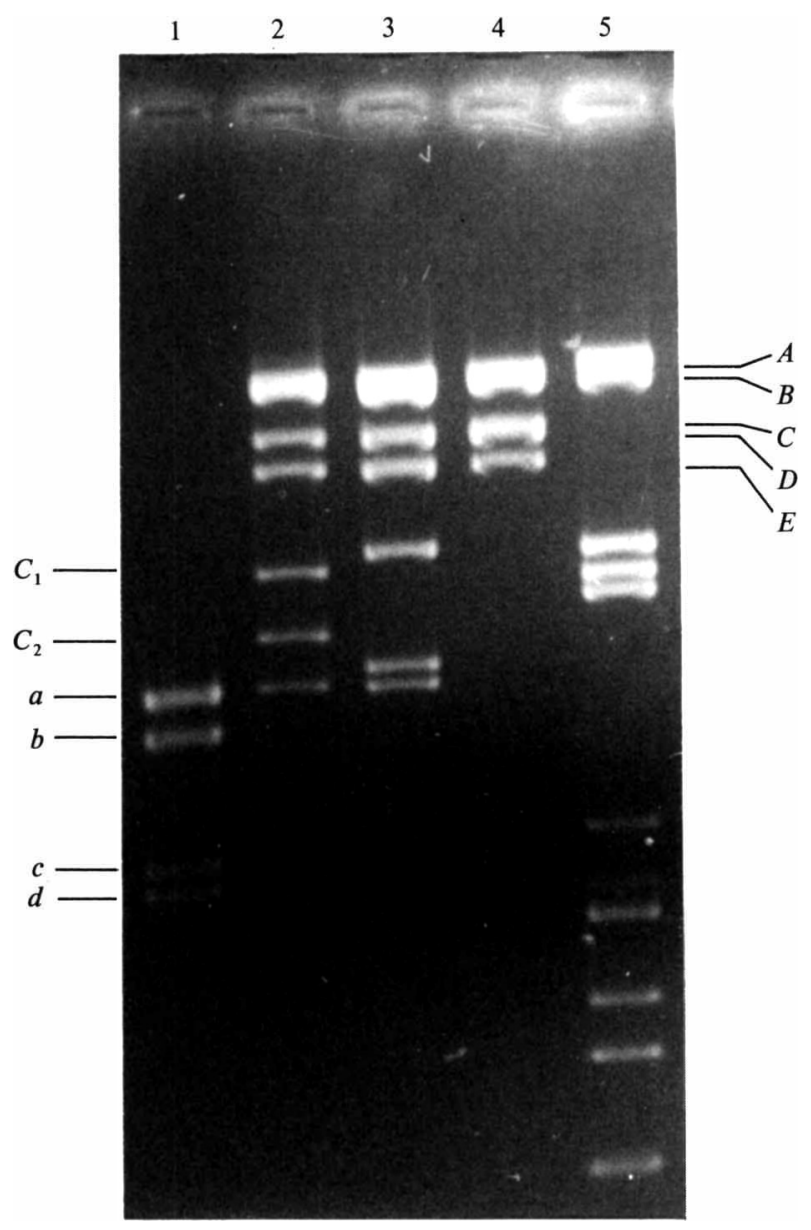

Fig. 2. PstI cleavage pattern of pBP153, pBP1531, pBP1532 and R751 (lanes 1,2,3 and 4, respectively). The size standard in lane 5 was produced by cleaving $\lambda$ DNA with PstI. The R751 fragments $A$ and $B$ and the fragments $C$ and $D$ (lane 4) form one band each, because of their similar size. Due to their small size, fragments $e$ and $f$ of pBP153 (lane 1) are not visible.

sequences, when they are in direct orientation, can transpose any DNA sequence if the intervening sequence is not too large. The influence of the size of the sequence between the IS elements on transposition frequency has been reported by Chandler et al. (1982) for ISI mediated transposons. The observation that the tetracycline resistance region of the plasmid N3 (about $11 \mathrm{~kb})$ does not transpose at a detectable frequency $\left(<3 \times 10^{-9}\right.$; Brown et al., 1984) is consistent with these findings. The lack of transposons flanked by inverted copies of IS 160 and related elements may reflect an inability of such segments to transpose, as demonstrated by the tetracycline and arsenate resistance region of R46 (Brown et al., 1984) and the arsenate resistance region of pBP16 (Nies et al., 1985), which do not transpose at a detectable frequency. Another possible reason for the inability of these segments to transpose efficiently is the size of the intervening sequence; the arsenate resistance region of pBP16 is $6.5 \mathrm{~kb}$ while the tetracycline and arsenate resistance region of R46 is more than $11 \mathrm{~kb}$.

This work was supported by a grant of the Deutsche Forschungsgemeinschaft to Bernd Wiedemann. 


\section{REFERENCES}

Bachmann, B. J. (1972). Pedigrees of some mutant strains of Escherichia coli K12. Bacteriological Reviews 36, 525-557.

BräU, B. \& PiePersberg, W. (1983). Cointegrational transduction and mobilization of gentamicin resistance plasmid pWP14a is mediated by IS140. Molecular and General Genetics 189, 298-303.

Brown, A. M. C., Coupland, G. M. \& Willetts, N. S. (1984). Characterization of IS46, an insertion sequence found in two IncN plasmids. Journal of Bacteriology 159, 472-481.

Chandler, M., Clerget, M. \& Galas, J. (1982). The transposition of IS $I$-flanked transposons is a function of their size. Journal of Molecular Biology 154, 229-243.

DEAN, D. (1981). A plasmid cloning vector for the direct selection of strains carrying recombinant plasmids. Gene 15, 99-102.

Foster, T. J., Davis, M. A., Roberts, D. E., TAKeshita, K. \& KleCKNER, N. (1981). Genetic organization of transposon $\operatorname{Tn} 10$. Cell 23, 201-213.

IIDA, S., HÄNNI, C., Echorti, C. \& ARbER, W. (1981). Is the IS 1 -flanked r-determinant of the $\mathrm{R}$ plasmid NR1 a transposon? Journal of General Microbiology 126, 413-425.

IIDA, S., MEYeR, J., LindNER, P., Goto, N., NAKAYA, R., REIF, H.-J. \& ARBER, W. (1982). The kanamycin resistance transposon Tn 2680 derived from the $R$ plasmid Rts 1 and carried by phage $P 1 \mathrm{~km}$ has flanking $0.8 \mathrm{~kb}$ long direct repeats. Plasmid 8, 187 198.
KleCKNER, N. (1981). Transposable elements in prokaryotes. Annual Review of Genetics 15, 341-404.

Labigne-Roussel, A. \& Courvalin, P. (1983). IS 15 , a new insertion sequence widely spread in $\mathrm{R}$ plasmids of Gram-negative bacteria. Molecular and General Genetics 189, 102-112.

Labigne-Roussel, A., Briaux-Gerbaud, S. \& CourVALIN, P. (1983). Tn 1525 , a kanamycin resistant $R$ determinant flanked by two direct copies of IS 15 . Molecular and General Genetics 189, 90-101.

Meyer, R. J. \& Shapiro, J. A. (1980). Genetic organization of the broad-host-range IncP-1 plasmid R751. Journal of Bacteriology 143, 1362-1373.

Meyer, J. F., Nies, B. A. \& WiedemanN, B. (1983). Amikacin resistance mediated by multiresistance transposon $\operatorname{Tn} 2424$. Journal of Bacteriology 155, 755 760.

Nies, B. A., Meyer, J. F., Kratz, J. \& Weidemann, B. (1985). R1767, an example of the evolution of resistance plasmids. Plasmid 13 (in the Press).

REIF, H. J. (1980). Genetic evidence for absence of transposition functions from the internal part of transposon $\operatorname{Tn} 981$, a relative of transposon $\operatorname{Tn} 9$. Molecular and General Genetics 177, 667-674.

Rosner, J. L. \& Gottesman, M. M. (1977). Transposition and deletion of $\operatorname{Tn} 9$, a transposable element carrying the gene for chloramphenicol resistance. In DNA Insertion Elements, Plasmids and Episomes, pp. 213-218. Edited by A. Bukhari, J. A. Shapiro \& S. Adhya. Cold Spring Harbor, NY: Cold Spring Harbor Laboratory. 